Revista de la red interuniversitaria de estudios sobre las literaturas rioplatenses contemporáneas en Francia

Hors-série | 2019

Ricardo Piglia: Cierta idea de literatura

\title{
El milagro secreto de Emilio Renzi: Otra vuelta a la novela del porvenir
}

\section{Sergio Waisman}

\section{OpenEdition}

\section{Journals}

Edición electrónica

URL: http://journals.openedition.org/lirico/7871

DOI: $10.4000 /$ lirico.7871

ISSN: 2262-8339

Editor

Réseau interuniversitaire d'étude des littératures contemporaines du Río de la Plata

\section{Referencia electrónica}

Sergio Waisman, «El milagro secreto de Emilio Renzi: Otra vuelta a la novela del porvenir », Cuadernos LIRICO [En línea], Hors-série | 2019, Puesto en línea el 16 febrero 2019, consultado el 10 mayo 2019. URL : http://journals.openedition.org/lirico/7871 ; DOI : 10.4000/lirico.7871

Este documento fue generado automáticamente el 10 mayo 2019

\section{(c) $(1) \ominus$}

Cuadernos LIRICO está distribuido bajo una Licencia Creative Commons Atribución-NoComercialSinDerivar 4.0 Internacional. 


\title{
El milagro secreto de Emilio Renzi: Otra vuelta a la novela del porvenir
}

\author{
Sergio Waisman
}

"Vivir como un viajero, alguien que llega siempre por primera vez a un lugar y no conoce a nadie." ( Los diarios de Emilio Renzi, III, 135)

\section{Viajes y traducciones en la literatura argentina: “La traducción es el espacio de los grandes intercambios y de las circulaciones secretas"}

1 En “La perspectiva exterior”, Juan José Saer dice:

“[B]uena parte de nuestra literatura [...] ha sido escrita por extranjeros en idiomas extranjeros [...]. Cuando todavía no teníamos literatura, ya viajeros europeos, marineros, científicos, comerciantes, aventureros, incluso espías, repertoriaban en informes, cartas, relatos, memorias, las características de nuestro suelo, de nuestro paisaje, de nuestra sociedad, de nuestras primeras diferencias con el resto del mundo". (1989: 12)

Me interesan ciertas semejanzas-parentescos, se podría decir-entre el lugar de los viajes y los viajeros (por un lado) y los traductores y las traducciones (por el otro) en la literatura argentina. De hecho, en la literatura en general. Las semejanzas entre un viaje y una traducción son muchas; viajar y traducir, ambos relacionados al errar del cuerpo y de la lectura, a cruzar fronteras, a un ir y venir, a estar dispuesto a salir en búsqueda y a sentirse perdido, a ser forastero, a sentirse extranjero, un tipo de outsider por excelencia.

Me gustaría tomar lo que dice Renzi en el tercer volumen de Los diarios de Emilio Renzi de Ricardo Piglia ("Vivir como un viajero, alguien que llega siempre por primera vez a un lugar y no conoce a nadie" (III, 135)) como punto de partida para explorar algunas de estas semejanzas -entre viajar y traducir, entre un viaje y una traducción- en ciertos momentos de la producción literaria de Ricardo Piglia de la última etapa de su vida. Y hacer esto precisamente como uno de los traductores de Piglia al inglés. Me interesan los 
puntos de contacto entre la mirada de los viajeros y los extranjeros (la perspectiva exterior, como la llama Saer), y la tradición de la mal-traducción (el trabajo con el mistranslation que se ve en Borges ${ }^{1}$, por ejemplo): un cruce que resalta, a mi modo de ver, los aspectos fronterizos de esta literatura. Puntos de contacto, propongo, claves para leer a Piglia, para leer con Piglia, una lectura "como un viajero, alguien que llega siempre por primera vez a un lugar y no conoce a nadie". En mi caso, desde afuera o, como mucho, parado en una frontera; cuando no sea del otro lado de la frontera.

Un cruce entre leer y andar donde el viaje y el traducir serían operaciones (métodos, ejercicios, prácticas, posibilidades) de irse. O quizás, un cruce entre leer y andar donde el viaje y el traducir serían operaciones de volver; aunque ese volver sea, a fin de cuentas, un volver imaginario. Miradas desviadas de (y con) Ricardo Piglia, pensadas como un caso paradigmático de esta compleja casi equivalencia entre viajar y traducir. Lo que sigue son algunas reflexiones basadas en mis experiencias como uno de los traductores de Ricardo Piglia al inglés, y también de un traductor que quiere escribir: a veces en inglés, a veces en castellano, casi siempre mal, o mejor dicho: nunca del todo como me gustaría, pero siempre con todo lo que tengo, por todo lo que haya perdido ... Siempre una copia, siempre tarde, siempre fuera de lugar, siempre extraviado, fronterizo, on the edge, on edge, under cover, under ... No sé. Siempre, lo digo así, buscando otra vuelta: buscando una vuelta posible a la novela del porvenir.

\section{Viajar y traducir, o un Irse en búsqueda de su corrección}

5 La traducción acelera el proceso de reproducción y circulación de textos, asumiendo así una función de disparador del fluir de los libros en nuevos circuitos. La traducción es un viaje (i.e., el texto ha viajado, cruzado fronteras lingüísticas y culturales y temporales, etc.); y la traducción hace posible el viaje (del lector que, con la traducción, viaja - por así decir, en la imaginación y en la página, etc.- al idioma y la cultura del texto fuente, leído en la lengua del texto meta).

6 Pienso esta analogía (esta equivalencia, casi) entre viajes y traducciones en la literatura rioplatense, aunque estoy seguro de que se podría expandir a otras literaturas latinoamericanas. A la vez como traductor y como lector de literatura del Sur en el Norte, y como un traductor que quiere escribir, la pregunta surge casi enseguida: cómo viajancomo se traducen-estas miradas desviadas afuera de la Argentina, en particular en inglés, en los E.E.U.U. En otras palabras, qué pasa con esta mirada desviada (la perspectiva exterior, como la llama Saer), cuando es traducida para viajar al extranjero; ¿qué pasa cuando los viajes y la mirada extranjera viajan de la Argentina al exterior, particularmente en traducción? ¿Qué pasa con el irse en otra lengua?

\section{Modos de cruzar fronteras: el entre de la errancia deliberada}

7 La traducción es un arte cuyo éxito depende de intentar ser lo más parecido a otro, un arte de querer ser otro para así convertirse en uno mismo; la traducción, sin embargo, es un texto que se define tanto por sus diferencias como por sus semejanzas con el texto fuente -diferencias que emergen como marcas que el traductor quiere y no quiere 
revelar-. Se trata de una invisibilidad que se hace visible entre líneas (lo que se entre-ve ...). Se trata de un silencio que se escucha en el hueco entre lo dicho y lo no-dicho (lo que se entre-escucha ...). Se trata de un texto escrito entre líneas (lo leído y re-escrito y releído; lo que se entre-lee y entre-escribe ...) -entre lenguas y culturas, y entre sujetos e identidades-.

8 Traducir es desplazarse. Además, cuando uno traduce, en el momento de traducir, uno habita dos lenguas y dos identidades, aunque sea momentánea e inestablemente. En este sentido, traducir es pluralizarse. Ser más que uno es incómodo y creo que así debería ser. Es incómodo, difícil y precario situarse en la frontera, en el límite de las transformaciones creadas por la traducción. Viajar de un lado al otro, penetrando en la otra orilla, por así decir, y saberse un outsider, un extranjero (un extra-en-cero), en cualquiera de las dos.

La traducción desplaza el texto y practica una especie de errancia deliberada. Hace errar a los textos, en ambos sentidos de la palabra errar: el ir de un lado al otro, el viajar de los textos, el cruzar fronteras lingüísticas y culturales, etc. Pero también está el error, el equivocarse, el mis-step, las distorsiones, las desviaciones (algunas intencionales, otras no; algunas visibles, otras no). De hecho, los errores y las equivocaciones importan, pero no siempre como uno anticiparía. Como ha dicho Ricardo Piglia sobre esta cuestión: "Habría que reflexionar sobre qué quiere decir leer mal; qué tipo de efecto puede producir una lectura que se desvía de lo que en principio pueden ser los sentidos dados del texto" (2011 Web). Piglia hizo este comentario recordando lo que dijo Borges en muchas ocasiones, que el primer libro que leyó fue el Quijote en inglés, y que cuando más tarde lo leyó en castellano le pareció una mala traducción. Piglia celebra la picardía de Borges, y propone que, además de su característica agudeza, Borges de hecho utiliza a la traducción como método disparador para investigar la potencialidad de lecturas productivas justamente por ser equivocadas. "Los libros recorren grandes distancias", agrega Piglia; "La traducción es el espacio de los grandes intercambios y de las circulaciones secretas" (2011 Web).

\section{¿Quién sale, cómo, y por qué? (0: Roberto Arlt, wherefore art you, Roberto Arlt?)}

Como traductor, como un lector de una tradición del Cono Sur, tratando de escribir en territorio extranjero (y sintiendo que todo territorio es, para mí, extranjero), siempre me ha interesado la cuestión de cuáles textos y autores son traducidos, quién viaja (quién sale) del Cono Sur y por qué, y cómo². Se trata de cuestiones de mercado, sin duda, pero también de formaciones de canon, de muchos estereotipos, de políticas culturales, de modas, de gustos. ¿Qué pasa con lo literario, qué pasa con el valor estético, me pregunto, en el mercado global de la traducción? Un tema complicado que daría para todo otro estudio (o más que uno), pero lo menciono aquí para tratar de contextualizar la recepción internacional más reciente de las últimas publicaciones de Ricardo Piglia.

11 Cuando años atrás traduje el relato "Luba" ${ }^{3}$, parte de Nombre falso, el desafío era: ¿cómo escribir en inglés un cuento de Piglia que tuviera ecos de Roberto Arlt, cuando ninguno de los dos existía en inglés antes de mi traducción y cuando la historia de Piglia pasaba por una traducción equívoca de "Las tinieblas" de Andreiev, en atribución apócrifa a Arlt ${ }^{4}$ La cuestión era la autoría de "Luba" una vez que "Luba" aparecía en inglés, como parte de Assumed Name, escrito por Ricardo Piglia (o por lo menos atribuido a Ricardo Piglia); es 
decir, qué ocurría con la autoría de la historia una vez que la falsa atribución y las reescrituras del cuento pasaban por el filtro de la traducción (mi versión, en otra lengua, con otro nombre falso). Al llevarlo al inglés se multiplicaba el efecto de la traducción (ya presente en el original), la autoría se difundía aún más, el desplazamiento aumentaba y se re-desplazaba, si se quiere, a un punto de des-ubicación muy lejos de casi cualquier concepto de texto definitivo.

de traducciones equívocas y desviadas - de una traducción española del ruso Andreiev, a una versión argentina de Piglia que cruza a Arlt con Borges y se lo atribuye a Arlt, y luego al inglés, a medida que yo intentaba imaginarme al Piglia de Nombre falso en mi inglés- se convertía en un juego de nombres, de identidades, de espejismos, fragmentados y cambiables. En este juego de nombres falsos (in that game of assumed names ), ahí caí cuando empecé a traducir a Piglia hace más de veinte años.

13 El desafío de escribir en inglés un relato de Ricardo Piglia que sonara como Roberto Arlt pasaba por la casi imposibilidad de imaginarse a Roberto Arlt en inglés. Porque Arlt viaja mal, por la dificultad de traducirlo - quizás incluso de leerlo- fuera de la Argentina (o por lo menos fuera del Cono Sur), fuera del contexto de la relación tensa y explosiva que establece Arlt con la tradición. Como ha dicho Piglia: "Roberto Arlt no ha logrado el reconocimiento internacional que merece, quizá porque su prosa es demasiado disruptiva y al traducirla -o al leerla fuera de contexto- se normaliza y pierde su eficacia" (2012 Web).

Para traducir a "Luba" tenía que imaginarme un cuento de Arlt en inglés, filtrado por las sutilezas del estilo de Piglia. Para imaginarme a Arlt en inglés me puse a leer a rusos en traducción, quería tener en mente algunos modelos (sintácticos, de tono, e incluso léxicos) en el proceso de reescribir a un Arlt falsificado, a través de Piglia, en traducción. El mismo Andreiev, Gogol, Dostoievski, entre otros, traducidos al inglés, sirvieron así como ejemplos de un posible estilo para "Luba", un estilo propuesto en otra lengua (en inglés ahora, sea de quién sea), con otro nombre que era y no era el mismo que antes.

Aquí la traducción sería un ejercicio de cruzar fronteras tratando de imaginarse un estilo inexistente en la otra lengua, un viaje sin saber a dónde se iba. O para decirlo de otra manera: teníamos un punto de partida, había un camino de ida y eso era todo. El viaje mismo - la lectura, la traducción - hace el camino, dibuja un mapa posible. El viaje mismo funciona así, si bien de un modo imaginario. $Y$ a veces más que solamente imaginario.

\section{El viaje en Piglia que siempre parece haber sido un camino de ida}

16 Hay muchos viajes en la obra de Piglia. Un poco como Juan Dahlmann en "El Sur" de Borges, los viajes en Piglia no son nunca solamente viajes geográficos, sino también viajes temporales, o conceptuales. Los viajes en Piglia son a la vez cruces físicos y metafísicos. Bastaría pensar en el viaje de Emilio Renzi en búsqueda de su tío Marcelo Maggi en Respiración artificial y también en el viaje de esta novela al pasado argentino (especialmente el siglo XIX y la época de Rosas) en búsqueda de pautas para intentar leer el presente. Esto, en el caso del viaje de Renzi en búsqueda de su tío ausente Maggi en Respiración artificial, como el lector recordará, en plena dictadura a fines de la década de 1970, en un porvenir incierto, pero con una convicción inequívoca en su existencia posible. 
Podríamos pensar en otro gran viajero de la obra de Piglia, el extraño protagonista parcial de La ciudad ausente, el personaje Junior, hijo de viajeros ingleses, que investiga la máquina y el museo en la novela. El lector recordará que Junior, el periodista investigador de La ciudad ausente, hace dos viajes: uno por los circuitos clandestinos de Buenos Aires, el otro por los cuentos de la máquina Elena, quien se encuentra en el Museo, centro de la novela y de la ciudad. Pero hablar de centro aquí es algo equívoco, ya que ni la novela ni la ciudad en este texto de Piglia contienen una cartografía fija; más bien, aunque las referencias geográficas y literarias sean verídicas, tanto la novela como la ciudad, por momentos, parecen vaciarse de estructura, ya sea que se conviertan en esqueleto de la misma, o que asuman una forma amorfa, como ocurre especialmente hacia el final del texto, en el cual entramos en un mundo plenamente textual, en forma del monólogo extendido de la máquina que narra y cita y transmite y transforma como si estuviera fuera de control. Además, de cierto modo, los dos viajes de Junior son el mismo (en un gesto paralelo al de "La muerte y la brújula"): Junior (y el lector con él) lee los cuentos de la máquina como si estuviera recorriendo la ciudad, a tal punto que la ciudad se convierte en una metáfora de la novela, y viceversa, ya que el mapa de la ciudad se constituye con la serie de ficciones que se originan en la máquina. Así, la red de cuentos, a medida que éstos se interrumpen y se cruzan como calles y avenidas, forma el enigma del texto y la textualización de la ciudad.

unior emprende el viaje por la ciudad futurística de la novela de 1992, en búsqueda de "La isla" y "Los nudos blancos", y también por las historias de la máquina (como el lector), donde viajar parece ser sinónimo de leer e interpretar. No sé si esta comparación resulte ser demasiado general, porque leer es una manera de viajar imaginaria, desde luego, pero en La ciudad ausente lo que llama la atención es que los viajes de Junior son como el procedimiento mismo de transformación de historias de la máquina de Macedonio Fernández. Es decir, como la maquinización de la mis-translation. Viajar es traducir y ambos son errancias: llenas de potencialidad y de incertidumbre, y de un querer casi sin fin.

El caso de Renzi y Maggi en Respiración artificial y de Junior en La ciudad ausente son sólo un par de los muchos ejemplos de viajes y viajeros en los libros de Piglia a lo largo de los años. Tenemos también el viaje de Renzi al "interior" (a la Provincia de Buenos Aires) para investigar el crimen en Blanco nocturno, novela en la cual el misterio central está conectado al viaje enigmático de Tony Durán al pueblo en medio de las pampas. Y tenemos las múltiples idas y venidas de Renzi por la Argentina (por la zona del Río de la Plata, más bien: Adrogué, Mar de Plata, Buenos Aires y La Plata, principalmente) y por ciertos barrios de la ciudad de Buenos Aires en Los diarios de Emilio Renzi. Y el hecho de que sabemos que Piglia mismo viajó mucho, y que vivió buena parte de su vida desde finales de los setenta hasta su jubilación de Princeton en el 2012 viajando entre la Argentina y los E.E.U.U., en una puesta en escena de los diálogos (y las tensiones) norte-sur que a la vez aparecían también en sus libros.

\section{El viaje en (y de) El camino de Ida}

En El camino de Ida, la novela de Piglia del 2013, el tema del viaje está anunciado desde el título mismo. La novela empieza con la invitación que Piglia recibe para enseñar un seminario de posgrado sobre W. H. Hudson ${ }^{5}$ en una prestigiosa universidad de New Jersey que suena como Princeton (pero no lo es). De ahí el thriller del misterio académico en la 
primera mitad de la novela, y el viaje al "corazón de las tinieblas", por así decir, de la cultura y las contraculturas estadounidenses en la segunda mitad $-\mathrm{y}$ todo desde la perspectiva extranjera de Renzi, funcionando aquí enteramente como el viajero sudamericano desplazado, siempre un poco perdido y fuera de lugar, un poco como Tocqueville en el norte, o Hudson, o Darwin, en el Sur-.

21 A lo largo de El camino de Ida, de hecho, la investigación de Renzi sobre el misterio secreto de Ida se presenta desde la perspectiva sumamente argentina (y rioplatense, diría yo) de Emilio Renzi. Por un lado, la perspectiva del outsider en la academia estadounidense y su investigación del terrorismo doméstico y de ideologías anti-establishment crean una serie de observaciones perspicaces sobre la sociedad de los E.E.U.U., sorprendentemente desde el punto de vista de un viajero sudamericano. El hecho de que Renzi haya sido invitado a enseñar un seminario sobre Hudson no es ninguna coincidencia. El paralelo se sugiere desde el comienzo (Hudson en la Argentina en el siglo XIX; Renzi en los E.E.U.U. a fines del XX) y se complica más aún con las referencias a Conrad más adelante. Joseph Conrad: escritor desplazado, literalmente desterritorializado, que escribió en su segunda lengua; escritor que hace del viaje no sólo el tema sino el mecanismo central de su narrativa.

Desde su llegada a New Jersey, las descripciones de Renzi están plagadas del extrañamiento y la inquietud del forastero: "No podía pensar en inglés, inmediatamente empezaba a traducir" (2013: 22), dice Renzi, resumiendo la experiencia conocida por todo viajero. Explicando su interés en Hudson, Renzi dice:

Me interesaban los escritores atados a una doble pertenencia, ligados a dos idiomas y a dos tradiciones. Hudson encarnaba plenamente esa cuestión. [...] Un hombre escindido, con la dosis justa de extrañeza para ser un buen escritor. "Me siento enancado en dos patrias, dos nostalgias, dos esencias. Debo rendirle homenaje a las dos, y tiene que serlo justamente con esos dos elementos que forman mi doble ubicuidad: nostalgia y angustia." Presentaba los problemas clásicos del que se educa en una cultura y escribe en otra. (36)

"Un hombre escindido, con la dosis justa de extrañeza para ser un buen escritor": ésta sería una descripción de Emilio Renzi (o de Ricardo Piglia) en los E.E.U.U. ¿O en el Cono Sur también? Un viajero como Hudson (que escribe), o un traductor (que lee mal y eso le sirve): la experiencia del sujeto que vive en dos mundos, entre lenguas, siempre fuera de lugar: como el bilingüe, como el inmigrante, como el traductor. La perspectiva particular del personaje se experimenta (se lee) en la lengua en sí, a medida que Renzi escucha las particularidades culturales del inglés a su alrededor (alrededor de Princeton, suponemos, en New Jersey). Este aspecto autoreflexivo, este aspecto meta-literario de la novela, en particular, de un castellano rioplatense en los detalles estilísticos idiosincráticos del narrador (es decir, de Renzi), sería especialmente difícil de traducir al inglés ${ }^{6}$.

\section{La extrañeza del traductor - mi extrañeza como traductor}

Quiero en esta breve sección hablar un poco sobre mi lugar - sobre mi extrañeza- como traductor al inglés, ya que el inglés de hecho es mi segunda lengua, aunque he vivido (y escrito) casi toda mi vida en inglés. Como un individuo principalmente bilingüe, bicultural, hijo de exiliados, producto de un irse constante, mi lugar como traductor es confuso (para mí mismo), y puede resultar equívoco (para otros). Pero el traductor es 
quien hace viajar los textos. No es el (o la) único/a. Pero sin traductores, sin traducciones, serían sumamente limitados los viajes de los textos y de la literatura en general.

Traducir es re-contextualizar. Traducir, se sabe, es desplazar un texto de una lengua y una cultura a otra lengua y otra cultura. Traducir, así, es una des-locación, una desorientación intencional y sin embargo (o quizás: y por lo tanto) también aporta el potencial de ser sumamente enriquecedor. La traducción crea al original. Traducir es decir lo mismo con una lengua diferente, como si uno fuera el otro, pero en la (llamada) lengua propia, como si la voz del otro estuviera, pudiera estar, en la boca de uno: una construcción imposible es la traducción y, no es de sorprender, según algunos, utópica. Fuera de lugar, fuera del tiempo: el traductor es un viajero que no encuentra puerto de destino. Como el lector, como el crítico, pero en una modalidad otra (¿diferente? ¿dislocada?). Como la modalidad del outsider perpetuo, ¿quizá? El traductor, quiera o no, siempre deja las huellas de su lectura en la traducción que escribe: ahí está, ahí aparece, por así decir, la estela en el agua a medida que avanza lenta y regular la canoa. Ahí está, ahí aparece, por así decir, la estela fugaz que es real mas se desvanece. Cuando uno lee una traducción puede entrever la lectura del traductor sobre la escritura original: sobre la escritura anterior. Cuando uno lee una traducción puede entrever los pasos de uno superpuesto en el otro, $y$ ambos a la vez.

Casi desde el principio, hace más de veinte años ya, me vengo preguntando cuál es la tarea del traductor de Piglia. ¿Qué hace, qué debería hacer el traductor frente a la constante reproducción y circulación de historias? ¿Cómo traducir toda una tradición, con sus múltiples intrigas y cruces, condensada y profunda, a otra lengua, donde esa tradición no existe? La solución, por lo menos la que yo he encontrado, reside en poner las historias en movimiento, dejar que se reproduzcan, intentar que se crucen con otras líneas, que hagan sus propios ecos, pero también que cobren nuevos significados, que la red con sus diferentes nudos sea otra (en otra lengua) para que los nudos sean los mismos, aunque transformados. Hacer migrar - hacer viajar- a los mismos nudos a otra red de asociaciones lingüísticas. Algo así es lo que he intentado hacer como uno de los traductores de Ricardo Piglia. Otro narrador, me pienso, viajando por la máquina transformadora de historias. $\mathrm{Y}$ a la vez reproduciéndola, con un poco de suerte y mucho esfuerzo.

También menciono, aunque dejo una reflexión (¿personal? ¿profesional?) más extensa sobre este tema para otro momento, la importancia de la conexión entre mi tarea como traductor y los viajes en mi vida y la de mi familia (los dos exilios de mis viejos, el ir y venir entre países y lenguas por varias generaciones ya, etc.). El viajero, como el traductor, como un outsider perpetuo; así lo veo y así lo vengo viviendo, si se quiere, yo ${ }^{7}$.

\section{Citar, copiar, analizar, traducir, leer: El caso de Ricardo Piglia y Emilio Renzi}

El crítico de la obra de Piglia se encuentra con la tentación de copiar a Piglia (porque Piglia es tan buen crítico él mismo, incluso si pensamos en su "crítica del escritor", como él decía). El crítico de Piglia debe enfrentarse a la tentación de copiar a Piglia. El traductor de Piglia, en cambio, tiene la obligación de copiar a Piglia. Mi relación con Piglia a lo largo de los años me ha posicionado entre estos dos imperativos, entre la tentación de copiar (o sea, de directamente citar) a Piglia, y la obligación (o casi la responsabilidad) de copiar a 
Piglia. ¿Cómo decir lo mismo en otra lengua? La consigna del traductor, interiorizada como un modo de ver el pasar del tiempo, desde otro lugar, a larga distancia. Al final, en mi caso, terminé confundiendo las dos cosas en más de una ocasión, hasta no poder reconocer yo mismo cuál era cuál: citar o copiar, grabar o transcribir, decir o traducir, escuchar o hablar, leer o escribir, soñar en una lengua como si fuera la otra y al revés también. Errar, equivocarse: buscar ahí los pasos de un camino por hacer. Esta errancia y esta equivocación (para mí como para otros, supongo), se confunde aún más con la reciente publicación de los tres volúmenes de Los diarios de Emilio Renzi.

"Se ha hablado toda la noche y él tiene los ojos vacíos. Vuelven a empezar. "Sólo la utopía permite pensar", se mueve en esa dirección. De lo contrario ¿qué queda? La resignación, el escepticismo" (III, 139), leemos en un momento del tercer volumen de los Diarios de Renzi. El potencial de la conversación, los ojos vacíos por haber hablado toda la noche o por lo que sea que le haya vaciado los ojos esa noche (no queda claro, el lector -nosotros - quedamos excluidos de ese detalle, pero a la vez, la ambigüedad aquí funciona para sugerir, la imaginación del lector -la nuestra- se amplía justamente en lo no dicho, en lo sugerido: ¿qué le habrá vaciado los ojos esa noche?). Y, ¿qué habrá sido lo que los lleve a volver a empezar, a retomar hacia una utopía que podría permitirles (permitirnos) pensar? Como si se volviera a Respiración artificial, o al siglo XIX argentino/sudamericano, o al XVII o el XVIII francés, todo (cualquier cosa) en una cita con forma tan breve, para que no quede "la resignación, el escepticismo". Y también está aquí la relación entre la oralidad y la escritura, que en la literatura argentina, y en particular en Piglia y su trabajo con la utopía, nos remite a Macedonio Fernández; más lo autobiográfico; y también el hecho de que yo mismo, Sergio Waisman, tuve varias de tales conversaciones con Piglia, y que algunas de ellas contribuyeron a mis traducciones y a una novela que acabo de terminar (El encargo) ...

\section{“Otórgame esos días, Tú de Quien son los siglos y el tiempo"}

Paso ahora - para hablar no sólo de Renzi sino también de Piglia, para tratar de hablar de Piglia del modo más franco posible, para mí por lo menos- a una breve comparación extravagante entre el final de la vida de Piglia y el final de la vida de Jaromir Hladík, el protagonista de la ficción "El milagro secreto" de Borges.

31 En la ficción de Borges, el milagro secreto ocurre justo en el momento en el cual Hladík, el estudioso escritor judío, está por ser fusilado por los nazis. Se lee:

Las armas convergían sobre Hladík, pero los hombres que iban a matarlo estaban inmóviles. El brazo del sargento eternizaba un ademán inconcluso. En una baldosa del patio una abeja proyectaba una sombra fija. El viento había cesado, como en un cuadro. Hladík ensayó un grito, una sílaba, la torsión de una mano. Comprendió que estaba paralizado. No le llegaba ni el más tenue rumor del impedido mundo. Pensó estoy en el infierno, estoy muerto. Pensó estoy loco. Pensó el tiempo se ha detenido. Luego reflexionó que en tal caso, también se hubiera detenido su pensamiento. (1996: 512)

Hasta ahí la ficción de Borges, en la cual a Hladík le es otorgado un año más para terminar su obra maestra: una obra invisible, inaccesible, mas no menos real por su invisibilidad. A Piglia, por su parte, le fue otorgado - para decirlo en términos utópicos que me gustaría pensar no lo incomodarían demasiado a él- aproximadamente tres años para terminar 
una obra maestra que deja de ser solamente invisible en lo que se convertiría en los tres volúmenes de Los diarios de Emilio Renzi.

"Dios operaba para él un milagro secreto [...] No trabajó para la posteridad ni aun para Dios, de cuyas preferencias literarias poco sabía. Minucioso, inmóvil, secreto, urdió en el tiempo su alto laberinto invisible" (512), dice el narrador de la ficción de Borges sobre la labor de Jaromir Hladík. Piglia, en cambio, en su tiempo fuera del tiempo, también inmóvil, también minucioso, creo que sí trabajó para la posteridad -aunque mejor sería decir para el porvenir: una carrera perdida contra el tiempo-; como Proust con las correcciones de A la recherche du temps perdu, o Saer con los últimos capítulos de La grande, Piglia urdió en el tiempo, por qué no, su alto laberinto: quizá como el fotógrafo de Flores olvidado en su taller en las afueras de una lejana capital sudamericana. La novela del porvenir de Piglia se transformaba, así, en lo que siempre esperábamos que fuera, y en algo más: la novela del porvenir de Piglia se transformaba -se transforma- en un milagro secreto para descubrir justo antes del final de todo. Para que el lector lo descubra (para que nosotros lo descubramos).

\section{Un baldazo de agua fría (= The ALS Ice Bucket Challenge)}

Me parece importante, casi imperativo, intentar decir algo sobre la esclerosis lateral amiotrófica (ELA en español, ALS en inglés), en particular dentro de esta lectura de Piglia/ Renzi como una versión literaria (Renzi), pero también demasiado real (Piglia) del personaje borgeano Jaromir Hladík. En otras palabras, parece importante decir algo sobre la enfermedad de Piglia y cómo él manejó esta condena fisiológica en los últimos años de su vida. Quiero decir algo sobre la espantosa enfermedad que le tocó a Piglia y la manera impresionante en que la confrontó. Quería intentar decir algo sobre la enfermedad y el final de la vida de Piglia, pero no sé si voy a poder, es muy triste y bastante reciente todo, pero a la vez me resulta increíblemente inspirador lo que hizo Piglia hacia el final y quiero intentar, por lo tanto, decir algo sobre todo esto.

Para mí como para otros, y sin duda más aún para los seres queridos de Piglia que estuvieron a su alrededor en los últimos años, era increíblemente difícil verlo en su estado reducido y cada vez más paralizado en términos físicos, incluso -o quizás, especialmente- sabiendo que su mente y su imaginación seguían tan vivas y vivaces como siempre adentro de su acelerada parálisis muscular. A la vez, ocurría algo impresionante ahí, eso también se notaba desde que la vida de Ricardo se empezó a achicar cada vez más, lo que por décadas habían sido sus incontables viajes y mudanzas, la increíble energía que siempre demostraba en sus innumerables actividades y compromisos, se limitaba ahora a la casa de la Calle Malabia donde lo cuidaban la fantástica Beba Eguía y un pequeño equipo de asistentes literarios y médicos. Ocurría algo impresionante, decía, porque era sin duda alguna deprimente, devastador, verlo así, saber que Piglia estaba así y que sólo empeoraría hasta el fin que ya se sabía lo esperaba y -a la vez- era sumamente inspirador ver, escuchar, cómo estaba lidiando -resistiendo- a través de la lectura y la escritura; desde cierto punto de vista, igual a lo que siempre había hecho Piglia a lo largo de su vida. Resistir el presente a través de la lectura y la escritura, "esperar" un porvenir que nadie sabía -que nadie sabe, de verdad- que tiene por qué llegar, mas igual "esperarlo": Piglia, el eterno utópico, incluso hacia el final, cuando se 
sabía que para Piglia no llegaría tal porvenir. Para Piglia no, pero quizá para Renzi sí; volveré a esta idea pronto; volveremos todos sus lectores a esta idea, sospecho, pronto, lo más pronto posible. Es decir, se puede pensar que Piglia entiende, hacia el final, que él ya no tiene futuro, e intuye, a la vez, que Renzi quizá sí, y por eso le deja todo a su personaje: o sea, por eso Piglia le atribuye sus propios cuadernos a su personaje en lo que será, en lo que ya es, en efecto, los Diarios de Emilio Renzi: para que busquemos, para rastrear allí esa novela del por-venir a la cual Piglia parecía siempre aludir en sus textos y conferencias.

Tony Judt, el gran historiador judío británico del siglo XX que vivió y escribió su trabajo más importante aquí en Nueva York (en NYU, de hecho, desde 1987 hasta su muerte en el 2010), quien también sufrió y falleció de ELA, la misma enfermedad que lo consumiría a Piglia, dijo sobre su enfermedad:

En efecto, la ELA constituye un encarcelamiento progresivo y perpetuo [...] La mejor manera de describir esta enfermedad es como una celda de prisión que se va achicando. No sabés cuándo va a hacerse tan chica que te va a aplastar hasta que te mueras. Sabés que esto va a ocurrir, la única incógnita es cuándo. Por lo tanto, la única pregunta que te tenés que hacer a vos mismo es: “¿Qué voy a hacer?”. (2010 Web; mi traducción)

La respuesta de Piglia a esta pregunta, ¿qué voy a hacer? (What am I going to do?), resultó ser una producción impresionante, incluyendo la relectura y la reescritura de sus legendarios cuadernos. La respuesta de Piglia parece haber sido, en efecto, terminar (i.e., releer, transcribir, reescribir) los 327 cuadernos ya conocidos como tales y a la vez atribuírselos a Emilio Renzi.

"ELA constituye un encarcelamiento progresivo y perpetuo", dice Tony Judt sobre el ELA y compara, en ese artículo que escribió para el New York Review of Books poco antes de su muerte, su propia situación con la del hombre transformado en bicho al comienzo de $L a$ metamorfosis de Kafka. A mí me hace pensar, además, y en el caso de Piglia en particular, en Prisión perpetua, pero en este caso se trataría del cuerpo individual y la condena sería literal, no sólo social o metafórica. Una prisión perpetua para el cuerpo y, a la vez, la lectura y la escritura como única salida posible: aunque realmente se trate de una salida imaginaria, conceptual y, por lo tanto, utópica.

\section{Un modo de concluir en breve con Renzi}

En un momento del tercer volumen de Los diarios de Emilio Renzi, se lee:

En un momento, una tarde cualquiera, se había dado cuenta, le decía Renzi a su médico personal, de que su dolencia pasajera era el resultado de los meses y meses que había dedicado a leer y a escribir sus diarios, hay muchas maneras de ser afectado y enfermar, y estaba seguro de que la exposición prolongada a la luz incandescente de su estilo le había provocado primero leves molestias, pero, como siguió adelante, la persistencia en una exposición de su cuerpo al brillo inigualable de la lengua argentina tenía, le dijo al médico, que producir efectos no deseados. La lengua argentina producía, como cualquier remedio o pharmacon o pócima mágica, sus contraindicaciones. No era sólo él, doctor, le dijo Renzi a su médico, el que había padecido en su cuerpo la presencia de su estilo al escribir, conocía otros casos. (III, 158)

Y a continuación, en la misma entrada, Renzi nombra a Borges, a Arlt, a Saer, a Puig. Y sí, nosotros también conocemos otros casos. Cuyas contraindicaciones podrían incluir, con persistencia y dedicación y un toque del azar, uno que otro milagro secreto. Lo que nos 
quedaría a nosotros - lo que nos queda a nosotros, a mi modo de ver- es agradecer a Ricardo Piglia (y a Emilio Renzi), y seguir discutiendo (y leyendo, y analizando, y traduciendo, desde luego) esta gran obra que nos ha otorgado.

\section{BIBLIOGRAFÍA}

Borges Jorge Luis, “El milagro secreto", Obras Completas 1, Barcelona, Emecé Editores, 1996, p. 508-513.

Judt Tony, "Night”, New York Review of Books, 14/01/2010, Web.

Piglia Ricardo, Nombre falso, Buenos Aires, Siglo Veintiuno Editores, 1975.

--- Respiración artificial, Buenos Aires, Editorial Sudamericana, 1980.

--- “Existe la novela argentina?”, Espacios de crítica y producción nº 6, 1987, Buenos Aires, p. 13-15.

--- La ciudad ausente, Buenos Aires, Editorial Sudamericana, 1992.

--- Assumed Name, Pittsburgh, Latin American Literary Review Press, 1995. Traducción de Sergio Waisman.

--- The Absent City, Durham, North Carolina, Duke University Press, 2000. Traducción de Sergio Waisman.

--- Blanco nocturno, Barcelona, Anagrama, 2010.

--- "Romance e tradução (conferência de Ricardo Piglia)", Companhia das Letras, São Paulo, Brazil, 26 de septiembre de 2011, Web.

--- "Tres libros son casi mi obra completa", Entrevista en línea con Jorge Luis Rodríguez Reyes, Esquife: revista de arte y literatura, 13 de julio de 2012, Web.

--- El camino de Ida, Barcelona, Anagrama, 2013.

--- Antología personal, México DF \& Buenos Aires, Fondo de Cultura Económica, 2014.

--- Target in the Night, Dallas, Texas, Deep Vellum Publishing, 2015. Traducción de Sergio Waisman.

--- Los diarios de Emilio Renzi, Volúmenes I - III, Barcelona, Anagrama, 2015 - 2017.

Saer Juan José, “La perspectiva exterior: Gombrowicz en Argentina”, Punto de vista n 35, 1989, Buenos Aires, p. 11-15.

Waisman Sergio, Borges y la traducción: la irreverencia de la periferia, Buenos Aires, Adriana Hidalgo Editores, 2005. Traducción de Marcelo Cohen.

--- El encargo, Buenos Aires, Editorial Mansalva, 2019 (fecha anticipada de publicación). 


\section{NOTAS}

1. Exploro el concepto del mis-translation (de la mal-traducción, o de la traducción equívoca y desviada) en profundidad en mi libro Borges y la traducción (2005).

2. En otras palabras, ¿por qué Borges sí y Arlt no? ¿Y cuál "Borges” precisamente es el que "sale" de la Argentina? También, por qué escritores como Ricardo Piglia y Juan José Saer, y Macedonio Fernández, para no ir más lejos, que han sido publicados en los E.E.U.U., pero en editoriales menores, mientras otros argentinos, Andrés Neuman y Luisa Valenzuela, por ejemplo, aparecen en editoriales más grandes, con mucha más circulación, etc. También sería interesante pensar aquí el caso de Alan Pauls y de Sergio Chejfec, o el de algunas de las escritoras que han tenido éxito internacional en los últimos dos o tres años.

3. El lector recordará que en Nombre falso, el "Homenaje a Roberto Arlt" concluye con el cuento "Luba", supuestamente un cuento hallado de Arlt, pero que resulta ser una versión adaptada de "Las tinieblas" de Andreiev, uno de los rusos que Arlt habría leído en traducción. Sabemos que Piglia reescribe el cuento de Andreiev como si fuera de Arlt, y se lo atribuye a Arlt, aunque el final de "Luba" es completamente diferente al final del cuento de Andreiev. El "Homenaje a Roberto Arlt" funciona, en parte, al realizar un robo y un tipo de plagio -a través de la traducción errónea y la atribución falsa- digno de Arlt, pero de Arlt cruzado con Borges, habría que decir, gracias a Piglia.

4. Ya Nombre falso problematiza la cuestión de la autoría, desde luego, a través de una serie errante de apropiaciones y atribuciones equívocas, a través de un trabajo sofisticado con la maltraducción (mis-translation).

5. Hudson: escritor fronterizo, entre Inglaterra y Argentina, entre inglés y castellano. Hudson: escritor fronterizo en más de un sentido, ejemplo ideal del entre que le interesa a Piglia/Renzi en Blanco nocturno, como le había interesado a Piglia en varios ensayos claves de Crítica y ficción, entre otros sitios.

6. Esto lo agrego basado en mis experiencias como uno de los traductores de Piglia al inglés. Entre mis e-mails con Piglia, hay varios sobre las dificultades que presentaría traducir El camino de Ida al inglés, incluyendo este caso en particular.

7. Dejo para otro lugar también mis reflexiones sobre algunos de mis viajes, y el cruce entre mis viajes (y las historias) personales y familiares, y los viajes (y las traducciones) de las historias de Piglia a lo largo de los últimos veinticinco años en los cuales lo conocí y trabajé con su obra.

8. "In effect, ALS constitutes progressive imprisonment without parole [... ] This disease is best described as being in a prison cell that gets steadily smaller. You don't know when it's going to get so small it's going to crush you to death. But you do know it's going to happen, the only question is when. So the only question you have to ask yourself is, 'What am I going to do"'.

\section{RESÚMENES}

Este artículo analiza el efecto de la publicación de Los diarios de Emilio Renzi en el concepto de la novela del porvenir de Ricardo Piglia. Una lectura parcial de los Diarios es puesta al lado de varios 
momentos de la obra de Piglia en los cuales se narra el proceso de escritura (casi invisible, principalmente secreta) de Renzi, desde Nombre falso, pasando por Respiración artificial, e incluyendo algo sobre los viajes de Junior en La ciudad ausente. El artículo está escrito desde la perspectiva de uno de los traductores de Piglia al inglés e incorpora observaciones y algunos ejemplos de su colaboración con Piglia a lo largo de los últimos veinticinco años, así como reflexiones sobre el trágico final de la vida de Ricardo Piglia (y de Emilio Renzi).

L'article analyse les effets de la publication de Los diarios de Emilio Renzi sur l'idée de «roman de l'avenir» de Ricardo Piglia. Il effectue une lecture de quelques entrées des Diarios, les mettant en parallèle avec des passages de l'œuvre de Piglia dans lesquels est narré le processus de l'écriture (presqu'invisible, surtout secrète) de Renzi ; ce parcours va depuis Nombre falso jusqu'aux voyages de Junior dans La ciudad ausente, en passant par Respiración artificial. L'article est écrit du point de vue d'un des traducteurs de Piglia en anglais et introduit des remarques et des exemples de la collaboration de l'auteur avec Piglia tout au long de vingt-cinq années, ainsi que des réflexions sur la fin tragique de la vie de Ricardo Piglia (et d'Emilio Renzi).

This article analyzes the effect of the publication of Los diarios de Emilio Renzi in the concept of Ricardo Piglia's "novela del porvenir". A partial reading of the Diarios is made next to several specific moments from Piglia's work, in which the process of writing itself (nearly invisible, primarily secret) is narrated by Renzi -from Nombre falso, through Respiración artificial, and including some of Junior's travels in La ciudad ausente-. The article is written from the author's perspective as one of Piglia's translators into English, and it incorporates observations and a few examples of his collaboration with Piglia from the last twenty-five years. It concludes with reflections about the tragic end of Ricardo Piglia's (and Emilio Renzi's) life.

ÍNDICE

Mots-clés: Piglia, Renzi, roman de l'avenir, voyages, traductions

Palabras claves: Piglia, Renzi, novela del porvenir, viajes, traducciones

Keywords: Piglia, Renzi, novel for/from the future, travels, translations

\section{AUTOR}

\section{SERGIO WAISMAN}

The George Washington University

waisman@gwu.edu 